\title{
"La Tacita de Plata": Aplicación de herramientas de RA a un Proyecto de Interpretación Patrimonial.
}

\author{
$>$ Mg. Arq. Ma. Magdalena Peña \\ Facultad de Arquitectura (UdelaR) Uruguay \\ magdalena76@montevideo.com.uy
}

\begin{abstract}
This article represents a summary of the final work to achieve the degree of "Master in Design, Management and Project for International Cooperation" of UEMC University. It consists of a project for heritage visualization of modern architecture in Montevideo, called "La tacita de plata". It main objective is to contribute to the knowledge of this valuable heritage by residents and visitors, and highlight its value as a source and reflection of a collective imagination that survives in our day and that we are heirs.
\end{abstract}

Keywords: Montevideo; Arquitectura; Interpretación Patrimonial; Realidad Aumentada.

\section{Arquitectura Moderna en Montevideo}

La introducción y desarrollo de las ideas de la Arquitectura Moderna en Uruguay y en Montevideo, en consonancia con las condiciones sociales, políticas y culturales de su época dieron lugar a la generación de un fenómeno único. Su importancia es tal que se considera oportuna su inclusión en la Lista del Patrimonio Mundial de la UNESCO, por parte de la Comisión del Patrimonio Cultural de la Nación

La modernidad uruguaya es abierta, desprejuiciada, integradora, posee cierta vocación de continuidad, opuesta a la de ruptura típica de las vanguardias europeas respecto a la inserción urbana de los nuevos productos, que se materializan en relación a un contexto concreto.

La Arquitectura Moderna en Montevideo es una arquitectura que genera ciudad, productora de experiencias que de a poco van completando el tejido urbano en una ciudad que crece de cara al futuro.

\section{El "Uruguay Moderno"}

El nacimiento del siglo XX encuentra al Uruguay en plena etapa de desarrollo.

El Estado, es concebido desde la óptica Batllista como el "escudo de los débiles” y debía siempre actuar en favor de los más desprotegidos. En este sentido es que se aprobaron leyes o se redactaron proyectos de ley, claramente de corte social y humanitario, avanzados para su época, incluso en comparación con países europeos.

Fue una época de bonanza económica (la Guerra Mundial tuvo mucho que ver), de expansión poblacional, de auge industrial, de optimismo.
El país y, por lo tanto, su capital y principal centro urbano, Montevideo, vivían un clima de bonanza económica -debida más que nada al alza de los precios de sus productos de exportación en los mercados mundiales- que permitió la acumulación de riquezas y el crecimiento hacia adentro.

La acción de un Estado protector permitió la distribución interna de esa riqueza a través del empleo (y obra) pública y de la seguridad social.

A estas particulares circunstancias externas, deben sumarse los cambios culturales y demográficos que operaron en la sociedad en su conjunto de la mano de la gran influencia de la inmigración, tanto externa como interna, ambas condiciones que fueron bien manejadas por el gobierno.

Desde ámbitos de la cultura subalterna, también ocurrieron hechos de insoslayable importancia nacional: las emblemáticas victorias futbolísticas de Ámsterdam, Colombes y Montevideo, seguramente contribuyeron grandemente al sentimiento de unidad, grandeza y confianza en el porvenir y en el progreso

\section{Identidad}

La Identidad Nacional es una construcción simbólica que reúne las características de tener cierta permanencia temporal, la necesaria existencia de un "otro" externo que le permita reconocerse en la diferencia, y la semejanza absoluta entre dos elementos internos.

Es la ideología quien proporciona un "lugar "desde donde apropiarse y ordenar la experiencia vivida y la que actúa como mediadora 
entre la historia y la cultura, para lograr un ordenamiento de ambas que permita llegar a la definición de la identidad colectiva.

Para Caetano (1992) en el proceso de construcción de la Identidad nacional se conjugan tres factores que él llama el "adentro" (los actores internos), el "afuera" (los actores externos) y el "prospecto" (la viabilidad posible del proyecto de identidad).

En ciertas oportunidades históricas se dan conjunciones excepcionales de uno o todos estos aspectos necesarios para la consolidación del constructo identitario, lo que los convierte en momentos de corte fundacional para la identidad de la nación, en que algunas de las características acuñadas por la particular situación histórica tendrán una permanencia mayor en el tiempo.

El mismo Caetano (1992) ubica cronológicamente uno de estos puntos de inflexión durante las tres primeras décadas del siglo XX, período en el que el proceso de construcción del modelo identitario uruguayo se completa, esta vez más que nada por presiones del "adentro", sin olvidar, por supuesto, las excepcionales condiciones de los otros dos factores (el "afuera" y el "prospecto"). Décadas que son, precisamente las de "Uruguay Moderno" y su Arquitectura Moderna.

\section{Identidad y Patrimonio.}

Una de las funciones sociales del Patrimonio Cultural es el de actuar como reforzador de la Identidad y como ligazón con el pasado y los orígenes de un imaginario que alcanza al presente.

Digamos entonces que todo lo que una cultura produce en un tiempo y un espacio dados y contextualizados históricamente, es reflejo y expresión de una ideología que está en la génesis de la identidad que esos mismos hechos construidos contribuyen a crear.

La Arquitectura, en tanto hecho construido, tiene la particularidad de ser reflejo y a la vez escenografía de los tiempos en que es creada, y por supuesto, constituye un legado permanente para las generaciones futuras, por lo es un fuerte generador de identidad a nivel territorial y social.

El optimismo y la confianza en el progreso de un país que mira al futura de que hablábamos al referirnos al "Uruguay Moderno", se simboliza en la renovación de los lenguajes arquitectónicos y la adopción de lo que podría llamarse "estilo" moderno.

El nuevo "lenguaje" fue el que se adoptó para la construcción de un nuevo universo de códigos visuales, recreado a partir de la ciudad construida, la que se percibe como un todo heterogéneo que incorpora y hace coexistir en su continuidad histórica las arquitecturas más diversas, y que puede leerse perfectamente como la nación que la produce, reproduciendo en cierta forma, sus características de igualdad en la diferencia y de fe incondicional en el progreso de la "Modernidad".

\section{Interpretación del Patrimonio y TICs}

Dentro de las herramientas de la Gestión Patrimonial la que tiene como finalidad funcional establecer el nexo entre el Patrimonio y la Sociedad, es la Difusión.

Es mediante la actividad de difusión del patrimonio que podemos transformar un objeto - o recurso - patrimonial en producto patrimonial.
El recurso patrimonial es el objeto físico, natural o cultural, que por alguna razón posee un valor destacable que le confiere el potencial para ser interpretado y explotado desde la óptica de un desarrollo social y económico sostenible.

El recurso de transforma en producto cuando sobre él aplicamos un plan estratégico de interpretación, presentación, exhibición, conservación y promoción, que permite llegar al visitante - consumidor con un mensaje elaborado a partir de pautas cognoscitivas, informativas y lúdicas.

Esta transformación requiere de la aplicación de un plan diseñado que respete los patrones de autenticidad histórica, material e identitaria.

Básicamente, la Difusión se vale de dos disciplinas para la presentación del Patrimonio al público: la musealizacion y la interpretación, que pueden aplicarse tanto en el contexto territorial del bien como externamente al mismo. Para ambas, el objetivo es el mismo, la concientización del visitante acerca de los conceptos de fragilidad -el patrimonio puede perderse - pertenencia - el patrimonio pertenece a toda la sociedad - y perdurabilidad - el patrimonio es una herencia para las generaciones futuras.

La Interpretación Patrimonial, que es la disciplina que nos ocupa, es el arte de trasmitir al público que visita un lugar que consideramos de valor patrimonial, y en el mismo sitio en el que el objeto se implanta, el significado cultural o histórico del bien, apelando para ello a códigos de fácil captación por parte del receptor, mediante una reelaboración de la información.

La interpretación es más que mera comunicación, es comunicación estratégica, pues tiene un objetivo por cumplir que es el de lograr la conexión intelectual y emocional del visitante con el bien visitado y es un "arte", porque involucra un proceso creativo.

Todo proyecto de Interpretación del Patrimonio, para ser calificado de tal, debe mantener las siguientes características:

- Ser entretenido

- Estar organizado, o sea que la comunicación mantenga una estructura que permita una recepción libre de esfuerzos y sencilla

- Tener un tema, que es el punto principal de lo que queremos comunicar acerca de un rasgo del patrimonio.

En la actualidad, el lenguaje audiovisual se ha vuelto una omnipresencia en nuestras vidas como vertebrador de la comunicación humana. Cada vez más necesitamos recibir información en forma de experiencia.

Causa o consecuencia de lo anterior es la actual explosión en el uso de las TICs (Tecnologías de Información y Comunicación), herramientas que permiten operar con la información posibilitando su tratamiento y trasmisión a través de soportes informáticos, más que nada Internet, y que se nos presentan como un valioso recurso aplicable al campo de la Interpretación Patrimonial.

Tal como expresa Ruiz Torres (2011):

El uso de las Nuevas Tecnologías en el campo del Patrimonio Cultural representa actualmente una novedosa y eficiente herramienta para su conocimiento y puesta en valor que ha llevado al desarrollo de importantes proyectos y experiencias 
cuyo principal objetivo ha sido potenciar las posibilidades y la difusión del objeto cultural. En este contexto, las Tecnologías de la Información y Comunicación (TICs), han cobrado un protagonismo latente, unido a la rápida implantación de dispositivos multimedia de bajo costo entre la sociedad, que han propiciado un crecimiento exponencial en el tratamiento e interpretación del Patrimonio Cultural haciendo posible el acceso al objeto cultural y la variedad de lecturas sobre el mismo destinado a un amplio sector de la sociedad, especialmente el relacionado con el denominado ocio cultural. (Ruiz Torres, 2011, p. 3)

Las TICs aplicadas a la Interpretación del Patrimonio Cultural cumplen con la necesaria acción mediadora, entre las dos partes intervinientes en el proceso perceptivo del mensaje: por un lado el emisor del mensaje, que es el propio patrimonio con sus valores asociados y, por el otro, los usuarios, sean estos residentes o visitantes, interesados en la obtención de un determinado conocimiento a partir de la experiencia y funcionan como soporte del proceso comunicativo, adquiriendo vital importancia en la difusión de los valores históricos, culturales, sociales y simbólicos de los entornos patrimoniales a los que se aplican.

De las múltiples tecnologías que pueden agruparse bajo la denominación general de TICs elegimos, por motivos estratégicos, las de Realidad Virtual y, más específicamente por su futura aplicación en el proyecto de interpretación que nos ocupa, la de Realidad Aumentada, derivada de la primera.

La Realidad Virtual (RV) es una aplicación informática que tiene por finalidad la generación o representación de entornos sustitutivos de la realidad, que existen solamente dentro del ordenador y son de factura totalmente artificial, buscando que el usuario experimente la sensación de estar presente en ese mundo virtual..

Por otra parte, la Realidad Aumentada (RA) es una tecnología derivada de la Realidad Virtual que se caracteriza por incorporar elementos virtuales en un espacio real gracias a la utilización de un determinado display. De este modo, la RA presenta un gran potencial en su capacidad de mejorar el espacio real que nos circunda mediante la incorporación de gráficos virtuales para lograr una imagen enriquecida de la realidad obteniendo así lo que llamamos "espacios aumentados".

Es, entonces, la combinación de imágenes reales y virtuales la principal característica de esta tecnología que no pretende sustituir a la realidad física que rodea al usuario sino complementarla, enriquecerla, "aumentarla", superponiéndole nueva información.

En cuanto a las aplicaciones de esta tecnología en el campo disciplinar de la interpretación Patrimonial, las primeras experiencias se relacionaron con actuaciones en yacimientos arqueológicos, sobre todo por las ventajas que demostró tener en lo referente a las reconstrucciones virtuales y a la difusión de las operaciones del tipo "antes y después".

La capacidad de incluir elementos virtuales en el espacio real y el desarrollo de interfaces de gran sencillez han convertido esta tecnología en un valioso recurso a la hora de buscar la interacción entre el usuario y el bien patrimonial, de forma atractiva y didáctica, permitiendo, además, dotar a los entornos patrimoniales de un sentido lúdico - racional y difundir estudios e investigaciones que de otra manera no llegarían al gran público.

Una de las ventajas que este tipo de aplicaciones informáticas presenta en cuanto a su accesibilidad al público en general es la que deriva de la evolución tecnológica a nivel de telefonía móvil y dispositivos portátiles de bajo coste (tablets y, para el caso concreto de Uruguay la incorporación de computadores personales través del "Plan Ceibal") y que posibilita el uso sencillo de sistemas basados en estas tecnologías mediante la introducción de un software determinado. La posibilidad de que cada usuario acceda a los contenidos aumentados a través de un dispositivo propio facilita la accesibilidad al objeto cultural y, por lo tanto, a su comunicación y difusión.

Frente a otras tecnologías similares, en particular frente a la RV, la RA tiene la notable capacidad de, por la misma razón de combinar lo real con lo virtual, permitir que el usuario no pierda en modo alguno el contacto con la realidad que lo circunda sino que, por el contrario, vive una experiencia de imagen enriquecida del objeto cultural., lo que la hace especialmente adecuada para su aplicación en entornos cotidianos (la ciudad, por ejemplo) más que a la de los estrictamente museológicos.

Por último, debemos rescatar que la RA hace posible el acceso a un espectro más amplio de de interpretaciones y lecturas del objeto y, por eso mismo, permite acrecentar los límites del conocimiento mediante reconstrucciones virtuales de elementos del pasado que son observados desde el presente de una forma realista y accesible. Cabe agregar que, por otra parte, su aptitud para incorporar gráficos generados por ordenador sobre el objeto real, constituye una solución absolutamente respetuosa, en términos ecológicos, de la conservación y preservación patrimoniales, valor que se añade al interpretativo, mencionado anteriormente.

"La Tacita de Plata": Proyecto de Interpretación del Patrimonio de la Arquitectura Moderna de Montevideo.

\section{Antecedentes}

La Arquitectura Moderna de Montevideo constituye un valioso Patrimonio material para nuestro país al punto de que es intención de la Comisión del Patrimonio Cultural de la Nación su postulación a la Lista Mundial de la UNESCO.

Sin embargo, a nivel del ciudadano común, este valor no es apreciado en su justa medida.

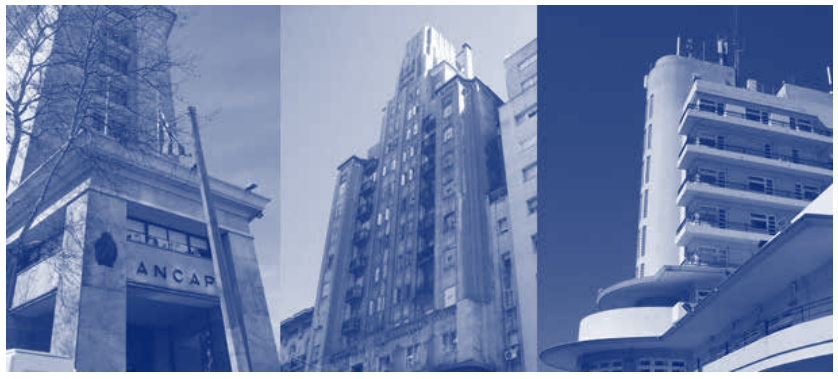

Figura 1: Arquitectura Moderna en Montevideo: Edificio ANCAP (Lorente y Valetti, 1944), Palacio Díaz (G. Vázquez Barriére y R. Ruano, 1929), Yatch Club (Crespi y Herrán, 1934) Fuente: wikimedia.com 
Creemos que si, con la aplicación de las medidas y herramientas que resulten pertinentes lográramos la identificación de la población con estas edificaciones y, además, su conocimiento más pleno, acabaríamos por consolidar un sentimiento de apropiación que resultaría invaluable a la hora de instaurar políticas de conservación y valorización de esos bienes patrimoniales.

\section{Comitente}

Comisión del Patrimonio Cultural de la Nación.

Facultad de Arquitectura de la Universidad de la República

\section{Objetivos}

- Lograr la valorización del patrimonio construido de la Arquitectura Moderna de Montevideo por parte de la población residente y visitante.

- Generar su reconocimiento como elemento fundacional y ambientador de la génesis de nuestro imaginario colectivo.

- Conversión de los recursos patrimoniales en productos patrimoniales susceptibles de ser explotados por un Turismo Cultural, interno y externo, en el marco de un plan de desarrollo sostenible.

\section{Resultados}

- Aumento de la valoración y de la identificación del patrimonio construido de la Arquitectura Moderna de Montevideo como parte de nuestra identidad cultural, hacia el interior y hacia el exterior de la ciudad.

\section{Producto final}

Proponemos el diseño de un Plan de Interpretación Patrimonial de la Arquitectura Moderna de Montevideo, que se apoye en las TICs y más precisamente en las aplicaciones de realidad aumentada (RA) para lograr sus cometidos, a través de la utilización de dispositivos móviles de bajo costo.

\section{Unidad operativa}

La Facultad de Arquitectura, a través del Instituto de Historia de la Arquitectura (IHA) y el Laboratorio de Visualización Digital Avanzada (VidiaLab), mediante la firma de un convenio con los desarrolladores del proyecto para la Comisión del Patrimonio Cultural de la Nación que actuaría como comitente final.

\section{Servicio a prestar}

- Aumento de la valoración del patrimonio de la Arquitectura Moderna de Montevideo por parte de los residentes a partir de su reconocimiento como parte de la identidad nacional

- Generación de un producto turístico que contribuya a la creación de una marca - ciudad.

\section{Conclusiones Generales.}

La aplicación de las herramientas de RA a un proyecto de Interpretación Patrimonial de la Arquitectura Moderna de Montevideo, se presenta tras el diseño del proyecto "La Tacita de Plata" como adecuada y totalmente viable en nuestro medio, gracias al acceso generalizado de la población y, sobre todo, de sectores estratégicos, a dispositivos móviles adecuados (Plan Ceibal).

Una de las limitaciones que hallamos para la implementación del plan, son las condiciones de propiedad de los inmuebles involucrados que, como ya expresamos en más de una oportunidad, puede ser una contrariedad importante y aún insalvable. De todas formas, muchos de los edificios propuestos son de uso público o semi-pública, incluso propiedad del Estado, por lo que, por lo menos parcialmente, la propuesta podría ser de correcta aplicación.

Por lo demás, consideramos que su viabilidad es grande por tener escasos impactos negativos a nivel del medio ambiente físico y social.

Confiamos, asimismo, en la posibilidad cierta de considerar este Plan de Interpretación Patrimonial con aplicación de herramientas de RA, como una experiencia piloto, capaz de replicarse en otros bienes patrimoniales de diferentes características, con la adecuada adaptación de los guiones de manera tal de diluir los costos y maximizar los beneficios de una experiencia que se evaluará o no como exitosa.

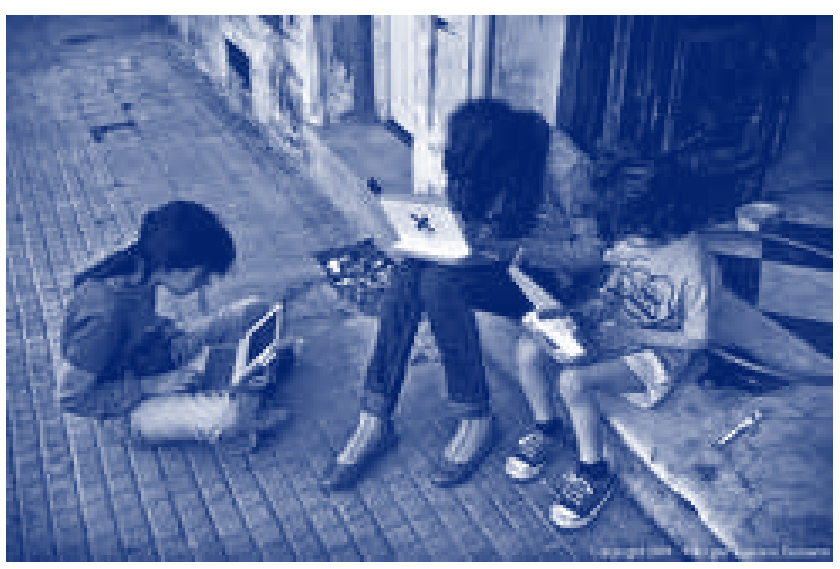

Figura 2: Plan Ceibal. Fotografía: Luciano Dossena

\section{Bibliografia}

ACHUGAR, H; CAETANO, C. (1992). Identidad uruguaya: ¿Crisis, mito o afirmación? Montevideo. Ediciones Trilce

ANDACHT, F. (1992). Signos reales del Uruguay imaginario. Montevideo. Ediciones Trilce.

REY, W. (2012). Arquitectura Moderna en Montevideo (1920 1960).Montevideo. Facultad de Arquitectura. Universidad de la República.

RUIZTORRES, David. (2011)." Realidad aumentada y Patrimonio Cultural: nuevas perspectivas para el conocimiento y la difusión del objeto cultural". Granada: recuperado el 7 de setiembre de 2013 de http://digibug.ugr.es/bitstream/10481/21792/1/ ruiz_torres_realidad_aumentada_y_patrimonio_cultural.pdf

RUIZTORRES, D. (2012). La realidad aumentada: un nuevo recurso dentro de las tecnologías de la información y la comunicación (tic) para los museos del siglo XXI. Granada. Recuperado el 1 de marzo de 2014 de http://www.publicaciones-encrym.org/ ojs/index.php/intervencion/article/viewFile/62/61 